\title{
Integrated LC filter on silicon for DC-DC converter applications
}

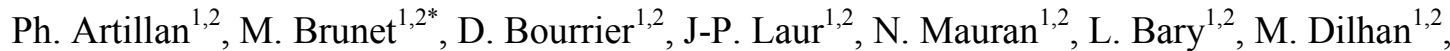 \\ B. Estibals ${ }^{1,2}$, Member, IEEE, C. Alonso ${ }^{1,2}$, Member, IEEE and J-L. Sanchez ${ }^{1,2}$, Member, IEEE \\ ${ }^{1}$ CNRS ; LAAS ; 7 avenue du Colonel Roche, 31077 Toulouse cedex 4, France. \\ ${ }^{2}$ Université de Toulouse ; UPS, INSA, INP, ISAE ; LAAS ; F-31077 Toulouse, France. \\ * Corresponding author : magali.brunet@laas.fr, phone: +33-561-33-7964
}

\begin{abstract}
The integration of passive components on silicon for future DC-DC converters applications is still a challenging area of research. This paper reports the microfabrication of a fully integrated filter containing a spiral inductor on top of a 3D capacitor. A thin magnetic shielding layer is introduced between the two components demonstrating that losses caused by the inductor in the capacitor area are reduced, thus increasing the maximum working frequency of the whole component. The fabricated filter was characterized in a test circuit (buck-type converter).
\end{abstract}

Index Terms-Integrated circuit fabrication, Electromagnetic induction, Inductors, Capacitors, Energy conversion, Magnetic shielding.

\section{INTRODUCTION}

The ever reducing size of electronic hand-held equipments combined with the increase in the number of functionalities, reveals a blocking point relative to the power management of systems. In embedded systems, switched-mode DC-DC converters can be used for supplying devices which do not require an extremely low noise supply voltage but are the most power consuming (e.g. memory chips, base-band cores, power amplifiers). Typical application ranges are input and output voltages less than $5 \mathrm{~V}$. For those high consumption devices, the converter has to provide an important output current: at least $100 \mathrm{~mA}$ and up to $1 \mathrm{~A}$, higher values being provided by several parallel converters. DC-DC converters will have to adapt to these new power requirements while being reduced in size and improved in terms of efficiency, cost and reliability.

The choice of the switching frequency depends on the size allocated to the DC-DC converter, the switching time limitation due to switch drivers and finally the global efficiency of the converter. The global efficiency is in turn affected by active losses (conduction and switching losses, required energy in drivers) and passive losses (conductors and magnetic core in inductors, equivalent series resistance in capacitors). Although it is difficult to propose a closed rule, today converters (discrete [1] and integrated [2], [3]) tend to work at switching frequencies less than $100 \mathrm{MHz}$ for about $100 \mathrm{~mA}$ output current, and less than $10 \mathrm{MHz}$ for about 1 A output current.

Passive components assuring storage and filtering (i.e. capacitors and inductors) are the bulkiest components of converters. Increasing the operating frequencies allows size reduction of these components. Studies have been carried out for embedding passive components on standard power devices substrates for applications from a few hundreds of milliwatts to a few watts: Printed Circuit Boards (PCB), Low Temperature Co-fired Ceramics (LTCC), on flexible substrates or directly "On-chip" [4]-[8]. For such low power applications, integrating passive components on silicon using microfabrication techniques thus becomes possible. The challenge for integrated passive components on silicon is therefore to allow high power density while keeping low losses at the operating frequency. Integrating inductors on silicon for DC-DC converter applications has focused research efforts for more than 10 years now [9]-[12]. The difficulty remains in producing thick conductors to reduce conductive losses and in integrating in the component a thin-film magnetic material with high resistivity, high saturation magnetization, and high in-plane anisotropy field [13], [14]. Similarly, high density integrated capacitors have been developed with either an optimization of the geometry of the structure: reduced dielectric thickness, enhanced electrodes area [15], [16] or the use of thinfilm dielectrics with a high permittivity such as $\mathrm{Ta}_{2} \mathrm{O}_{5}$ [17], [18], $\mathrm{Al}_{2} \mathrm{O}_{3}$ [17], $\mathrm{HfO}_{2}$ [19], $\mathrm{ZrO}_{2}$ [20], STO [21, 22], BST [23], PZT [24].

Integrating both passive components on the same substrate and thus creating an integrated filter is a way to push the integration a step further while reducing losses through connections and increasing reliability. Considering the range of frequencies mentioned above 
and, simultaneously, relatively low power, the task is feasible. For instance, a $45 \mathrm{MHz}$ converter with fully integrated output filter was reported in [6]: the required values for the passive components $(6 \mathrm{nF}$ and $11 \mathrm{nH})$ were reduced by two compared to state-of-the-art converters. More recently, Bergveld and al. [3] have shown the characteristics of an inductive step-down converter operating at $80 \mathrm{MHz}$ with integrated passive components (output LC filter and decoupling capacitor). The capacitors were realized by etching deep pores in the silicon to enhance the electrodes specific area [15], achieving $80 \mathrm{nF} / \mathrm{mm}^{2}$ capacitance density and the aircore inductors were realized in the $8 \mu \mathrm{m}$ thick copper top metal layer [25].

In this paper, we present the realization of an integrated output LC filter dedicated to future DC-DC micro-converters with the following characteristics: 560 $\mathrm{nF} 3 \mathrm{D}$ capacitor based on a process developed in [26] on top of which is realized a $110 \mathrm{nH}$ spiral micro-inductor based on processes developed in [27] and [28]. The total footprint of the filter is $9 \mathrm{~mm}^{2}$. The impedances of the capacitor and inductor of the fabricated filter were measured on a wide range of frequencies. In particular, the interest of a magnetic shield layer is investigated to reduce eddy current losses induced in the capacitor by the micro-inductor. Finally, the full LC filter was tested under real conditions, i.e. with square waveforms typically found in buck DC-DC converter architecture and its losses were analyzed.

\section{FABRICATION PROCESS}

The LC filter schematic top view and cross-section view are shown in fig. 1 . The device area is $3 \mathrm{~mm} \times 3$ $\mathrm{mm}$.

(a)

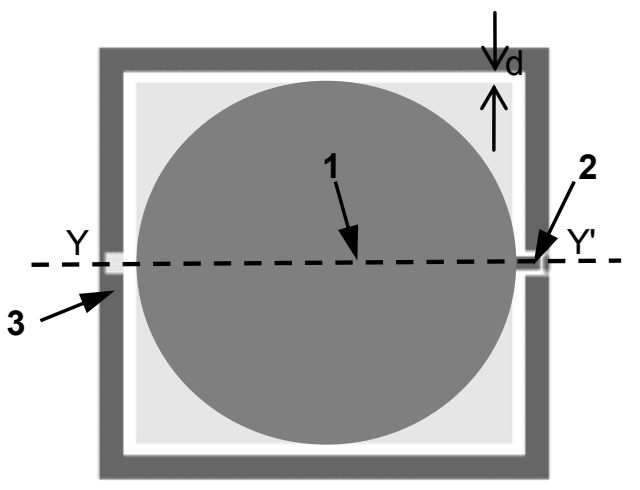

(b)

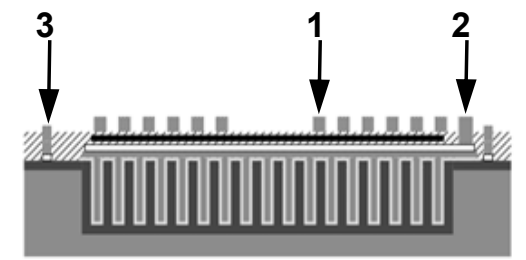

Fig. 1. Schematic (a) top view and (b) cross-section view along (YY') of the integrated LC filter.
The technological steps are reported in fig. 2. From (a) to (e), the 3D capacitor steps are detailed. In step (a), the bottom electrode of the capacitor is formed: high aspect ratio pores are etched by DRIE (Deep Reactive Ion Etching) in the silicon substrate and a phosphorus diffusion step (by $\mathrm{POCl}_{3}$ ) is applied. Then, in step (b), a dielectric $\left(\mathrm{SiO}_{2}-\mathrm{Si}_{3} \mathrm{~N}_{4}\right.$ bilayer $)$ is formed by a dry oxidation step and by LPCVD (Low Pressure Chemical Vapor Deposition) of silicon nitride. In step (c), the top electrode of the capacitor is realized: a boron-doped polysilicon $\left(2.10^{20} \mathrm{at} / \mathrm{cm}^{3}\right)$ is deposited by LPCVD, with a resistivity of $1.5 \mathrm{~m} \Omega . \mathrm{cm}^{2}$ and patterned.

The dielectric layer is also patterned (step d) and a $\mathrm{Ti} / \mathrm{Au}$ layer is deposited by sputtering to form ohmic contacts (step e). Steps (f) and (g) are the intermediate steps between the capacitor and the inductor. In step (f), an insulation layer made of SU-8 photoresist is spin coated and openings are provided to connect the inductor to the capacitor. In step (g), a thin layer of CoNiFe [28] is electrodeposited followed by copper electrodeposition to bring contacts to level. Finally, steps (h) to (i) are the steps concerning the spiral inductor. In step (h), an insulation layer made of SU-8 photoresist is spin coated and openings are provided. The spiral shape windings are then electrodeposited with copper through $50 \mu \mathrm{m}$ thick photoresist molds (step i). A gold flash $(50 \mathrm{~nm})$ is finally realized after copper deposition.

The fabrication steps of the capacitor (from step a to step d) are CMOS compatible and can be accommodated in the process flow of power components, as demonstrated with MOSFETs in [29] for self power supply application. The magnetic shield and the microinductor are typical back-end processing steps. Additional steps, required and not shown here, are the deposition of a passivation layer and of an additional metal layer for electrical feed through, and eventually the finishing with solder bumps for flip-chip. In this work, the components are directly cut after step i, i.e. without passivation layer and wire-bonds connect points (1), (2) and (3) to external pads.

\section{RESULTS}

In this section, the technological developments and the electrical performance of the capacitors and the inductors are analyzed separately before discussing the performance of the LC filter.

\section{A. $3 D$ capacitors}

Studies on creating high aspect ratio pores in silicon by DRIE were done on a STS equipment with an ICP (Inductively Coupled Plasma) source for high density plasma [30]. The Bosch process was optimized to obtain 
(a)

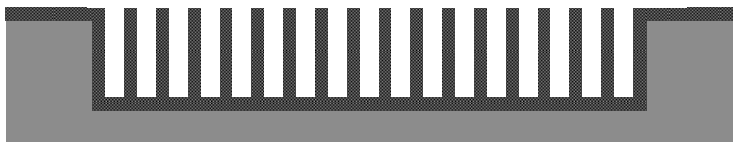

(b)

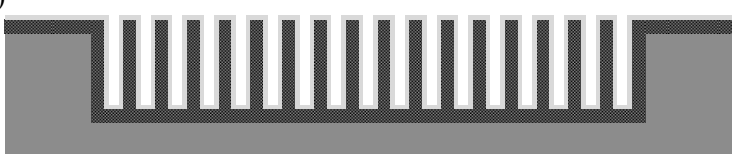

(c)

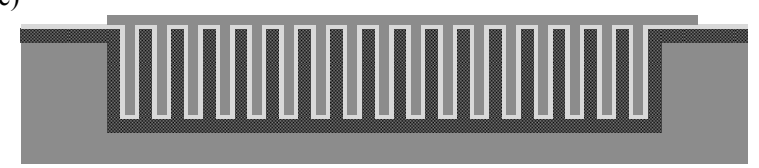

(d)

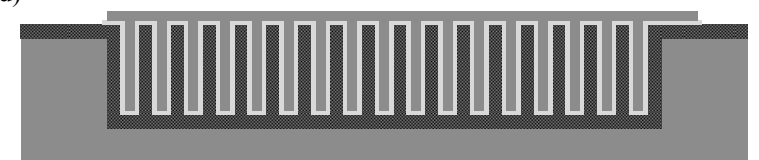

(e)

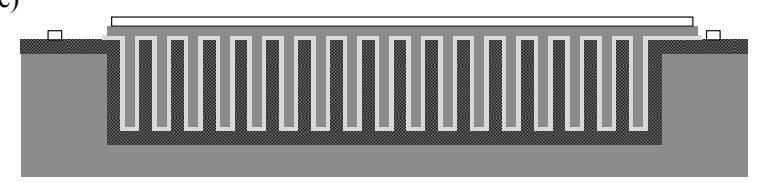

(f)

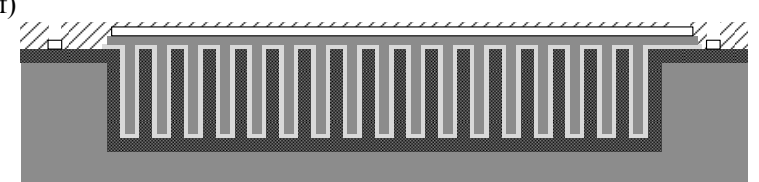

(g)

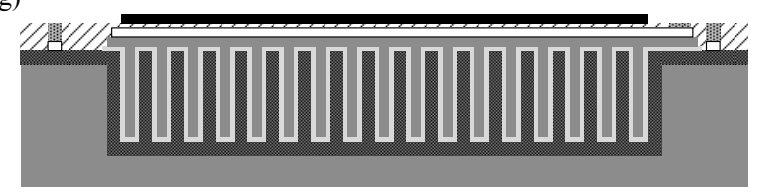

(h)

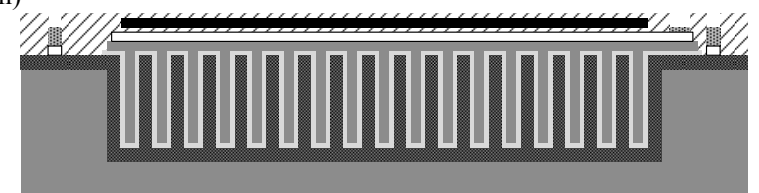

(i)

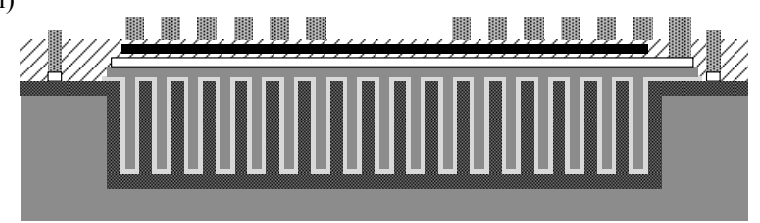

Fig. 2. Schematic (a) DRIE in Si substrate and $\mathrm{POCl}_{3}$ diffusion; (b) Oxidation (SiO2) and LPCVD of $\mathrm{Si}_{3} \mathrm{~N}_{4}$; (c) LPCVD of boron-doped polysilicon; (d) Dielectric layer patterning; (e) Ti/Au deposition; (f) SU-8 spin coating; (g) $\mathrm{CoNiFe}$ electrodeposition and $\mathrm{Cu}$ electrodeposition on the contact areas; (h) SU-8 spin coating; (i) Thick $\mathrm{Cu}$ electrodeposition.

high density pores network that allows high density capacitance [31]. A photoresist mask was used for the (a)

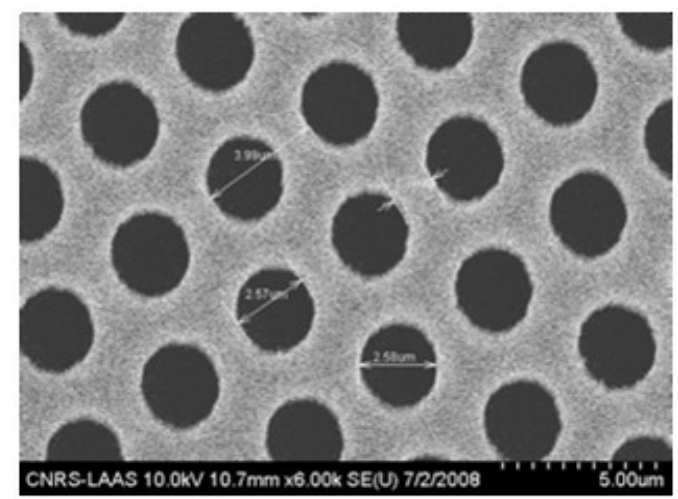

(b)

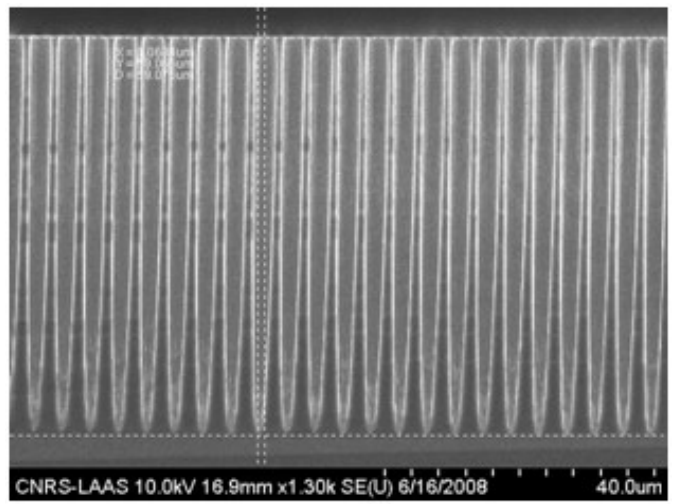

Fig. 3. SEM views of high aspect ratio pore network (a) top view, (b) cross-section: depth is $60 \mu \mathrm{m}$, width is $2.6 \mu \mathrm{m}$.

etching process. Figure 3 shows a SEM (Scanning Electron Microscope) view of a sectioned high aspect ratio pore network. At the end of the process, the width $w$ and the depth $h$ of the pores measured by SEM Hitachi S-4800 were $\mathrm{w}=2.6 \mu \mathrm{m}$ and $\mathrm{h}=60 \quad \mu \mathrm{m}$ respectively. An additional treatment with TMAH + IPA (Tetramethyl Ammonium Hydroxide + Isopropyl Alcohol) was applied [32] to remove the scalloping and to widen the top of the structures. This treatment is beneficial for subsequently filling the pores with polysilicon without forming void. A phosphorus diffusion step is done at this stage to decrease the access resistance of the capacitor bottom electrode.

N-type silicon substrates with two different initial doping: $10^{12} \mathrm{at} / \mathrm{cm}^{3}$ and $10^{19} \mathrm{at} / \mathrm{cm}^{3}$ constituted the bottom electrode of the capacitor. On each of these substrates, the phosphorus diffusion step was applied: $\mathrm{POCl}_{3}$ at $1500^{\circ} \mathrm{C}$ for $25 \mathrm{~min}$. As a consequence, a highly doped layer: $10^{21}$ at $/ \mathrm{cm}^{3}$ is formed at the surface with a depth of $1.5 \mu \mathrm{m}$. This has been checked by Secondary Ion Mass Spectrometry (SIMS).

At the end of step (e) (cf. fig. 2), the fabricated 3D capacitors were measured with impedance analyzer Agilent 4294A connected to RF probe Agilent 42941A. Figure 4 shows the impedance module of 3D capacitors 
of different sizes and for different initial substrate doping $\mathrm{N}_{\mathrm{d}}=10^{12} \mathrm{at} / \mathrm{cm}^{3}$ and $\mathrm{N}_{\mathrm{d}}=10^{19} \mathrm{at} / \mathrm{cm}^{3}$.

The capacitance is $558 \mathrm{nF}$ for $3 \mathrm{~mm} \times 3 \mathrm{~mm}$ size capacitor corresponding to $62 \mathrm{nF} / \mathrm{mm}^{2}$. The ESR (Equivalent Series Resistance) for an initial doping of $10^{19} \mathrm{at} / \mathrm{cm}^{3}$ is lower than for $10^{12} \mathrm{at} / \mathrm{cm}^{3}$. Therefore, despite the doped region $10^{21} \mathrm{at} / \mathrm{cm}^{3}$ at the surface, the substrate doping underneath still has a large effect over the series resistance. As a result, for instance, the larger capacitor keeps its capacitive behaviour until $3 \mathrm{MHz}$ when the substrate initial doping is $10^{19} \mathrm{at} / \mathrm{cm}^{3}$ as opposed to $800 \mathrm{kHz}$ when the substrate initial doping is $10^{12} \mathrm{at} / \mathrm{cm}^{3}$. To establish with precision the value of the ESR for each case, measurements with Kelvin probes (Microworld PTA-73APT25-50) were conducted. Figure 5 reports the measured ESR for $3 \mathrm{~mm} \times 3 \mathrm{~mm}$ capacitors. It is $0.17 \Omega$ for the highly doped substrate and $0.37 \Omega$ for the weakly doped substrate corresponding to $0.015 \Omega . \mathrm{cm}^{2}$ and $0.03 \Omega . \mathrm{cm}^{2}$ respectively. This series resistance is dominated by the access resistance in the doped silicon substrate between the bottom electrode contact (outside ring) and the top electrode contact (polysilicon square), represented in fig. 1 by the distance $d$. This access resistance could be further reduced by decreasing the corresponding distance or proposing a distributed electrodes configuration as in [33]. Another identified solution could be the use of a metal layer, such as TiN in [22] and [34], for the capacitor electrodes instead of doped silicon.

Other measurements were conducted on the 3D capacitors: $C(V)$ and $I(V) . C(V)$ characteristics reveal that there is no capacitance variation when a DC bias is applied. I(V) characteristics measured with a Keithley SC4200 reveal a breakdown voltage of $9 \mathrm{~V}$ for these capacitors.

\section{A. Micro-inductor developments}

Similarly to 3D capacitors, integrated inductors were first analyzed separately with different configurations. As a 3D capacitor is composed of conductive areas (bottom and top electrodes), it is likely that an inductor directly realized on top of it would develop eddy current losses in the foresaid areas: it was clearly shown in reference [3]. We thus investigated the introduction of a magnetic thin layer acting as a shield to prevent interaction between the inductor and the substrate/capacitor. The influence of the magnetic layer on the inductance and resistance of the micro-inductor was tested on prototypes without capacitor but where the silicon substrate was highly doped $\left(10^{21} \mathrm{at} / \mathrm{cm}^{3}\right.$ at the surface).

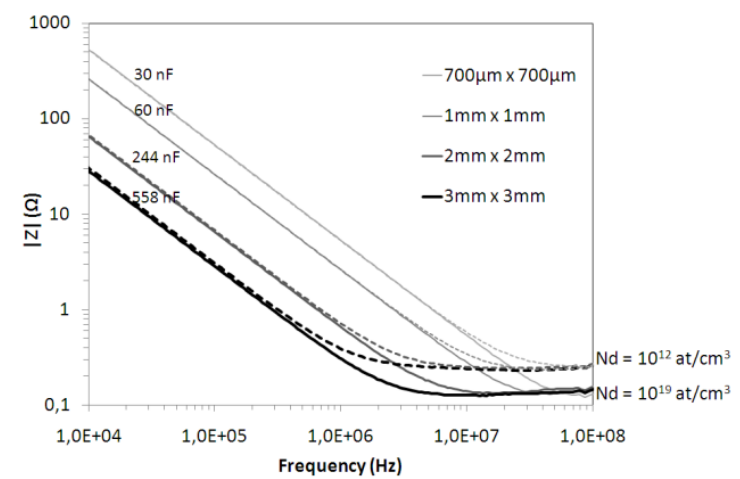

Fig. 4. Measured impedance module versus frequency for different sizes 3D capacitors. Dashed and plain lines correspond to substrate doping of $10^{12} \mathrm{at} / \mathrm{cm}^{3}$ and $10^{19} \mathrm{at} / \mathrm{cm}^{3}$ respectively.

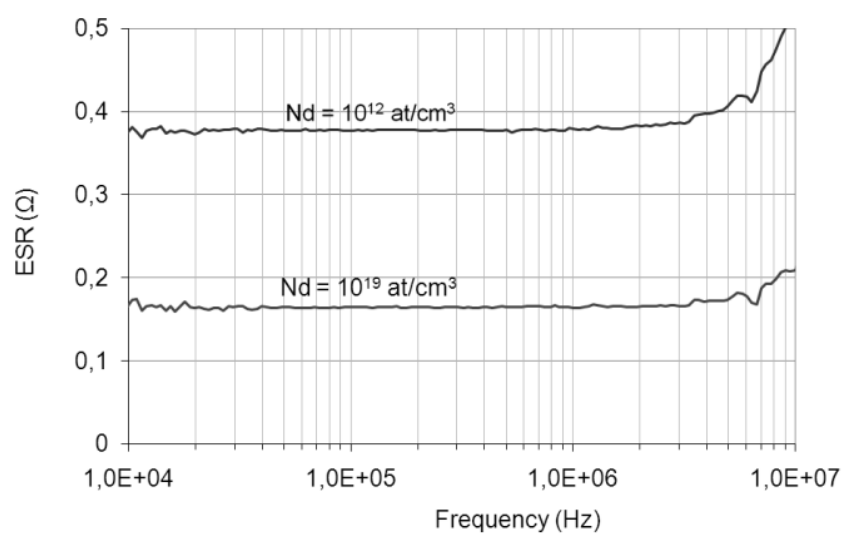

Fig. 5. Equivalent Series Resistance (ESR) of 3D capacitors versus frequency for two types of substrate doping measured with Kelvin probes.

Figure 6 shows pictures of the inductors realized with the magnetic layer $(\mathrm{CoNiFe})$, with and without lamination. The micro-inductors windings were composed of 8 turns, $78 \mu \mathrm{m}$ wide, separated by $72 \mu \mathrm{m}$. The electrodeposited copper windings were $51 \mu \mathrm{m}$ thick. For comparison purposes, a micro-inductor without magnetic layer was fabricated: in this particular case, the copper windings were $26 \mu \mathrm{m}$ thick.

Characterizations of the fabricated integrated inductors were done on an Impedance Analyzer (Agilent 4294A) with an RF probe (Agilent 42941A) from 10 $\mathrm{kHz}$ up to $1 \mathrm{MHz}$ and on a network analyzer (Rhode \& Schwartz ZVRE.) from $1 \mathrm{MHz}$ up to $4 \mathrm{GHz}$. Figure 7 shows the equivalent series inductance (ESL) and resistance (ESR) for the following cases: no magnetic layer, a magnetic layer ( $2 \mu \mathrm{m}$ thick), and a laminated magnetic layer. 
(a)

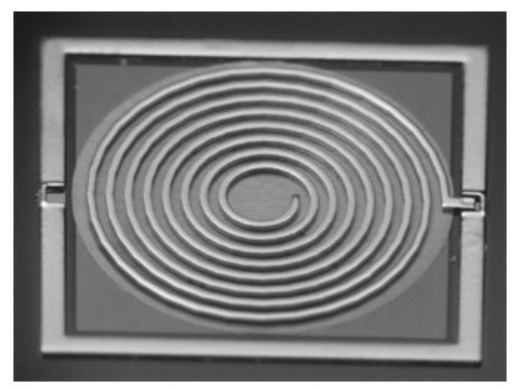

(b)

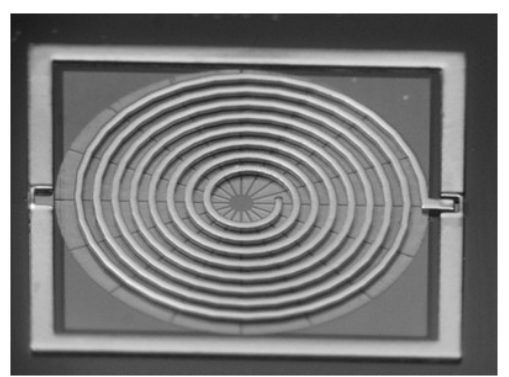

Fig. 6. Optical pictures of micro-inductor with magnetic shield (a) plain; (b) laminated.

(a)
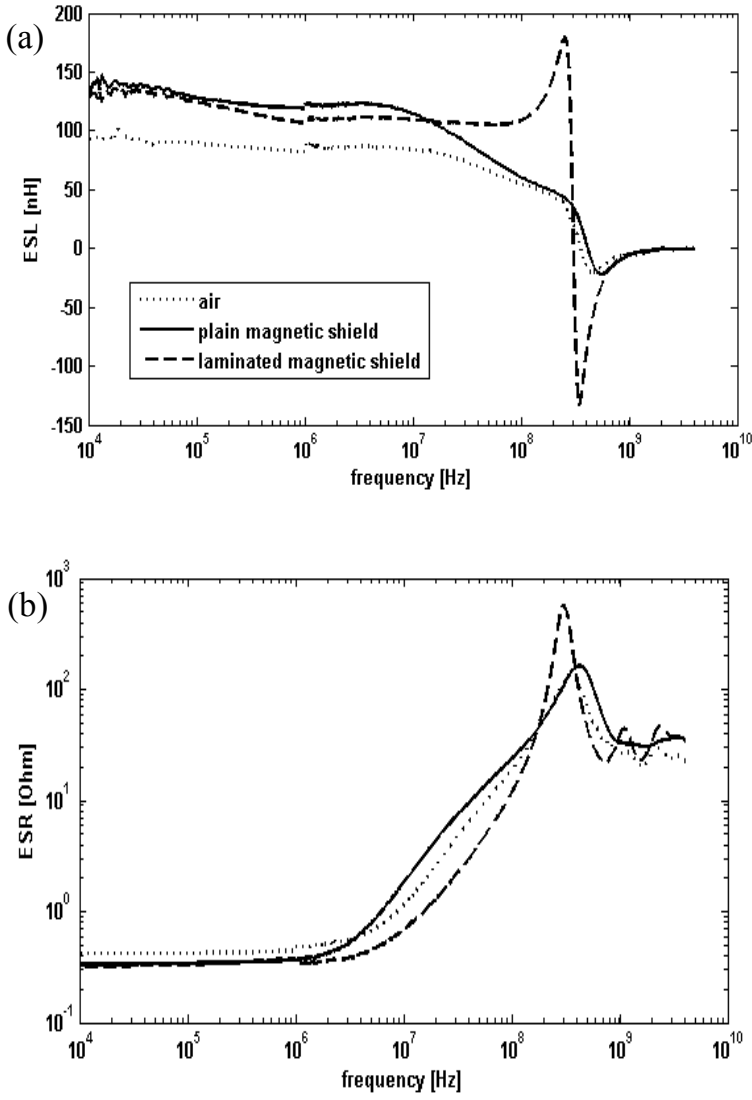

Fig. 7. Equivalent series inductance and resistance measured with impedance analyzer below $1 \mathrm{MHz}$ and with network analyzer above $1 \mathrm{MHz}$ for three types of inductors: no magnetic layer, a plain magnetic layer, and a laminated magnetic layer.
As expected, the inductance of the air micro-inductor is lower $(85 \mathrm{nH})$ than the inductance of the microinductor with magnetic layer underneath $(120 \mathrm{nH})$. On the other hand, the DC resistance for the air microinductor is $430 \mathrm{~m} \Omega$ while for the micro-inductors with magnetic layer, it is $320 \mathrm{~m} \Omega$. This is clearly explained by the conductors section which is higher in the latter case.

For AC features, it is clearly shown on the curve corresponding to the air micro-inductor that, above 10 $\mathrm{MHz}$, induced eddy currents in the substrate are responsible for the inductance decrease and the resistance increase. If a magnetic layer is introduced, eddy currents are then occurring in the magnetic layer. As a result, the ESL also decreases and the ESR increases. In the case of laminated magnetic layer, the inductance is not much lower than in the case of non laminated magnetic layer $(110 \mathrm{nH}$ versus $120 \mathrm{nH})$, however, it remains constant up to $110 \mathrm{MHz}$ (just before resonance frequency which occurs at $400 \mathrm{MHz}$ ) as opposed to $10 \mathrm{MHz}$ for non laminated layer. The ESR of the inductor with laminated magnetic layer is also lower: $540 \mathrm{~m} \Omega$ at $10 \mathrm{MHz}$ versus $2.1 \Omega$ at $10 \mathrm{MHz}$ for the plain one.

Saturation characterizations were also conducted on the three types of micro-inductors. The inductance versus DC current at $1 \mathrm{MHz}$ is shown in figure 8 . The inductance value is stable for the air-type inductor throughout the whole DC current range. For inductors with magnetic shield, the inductance is reduced by about $10 \%$ under $1 \mathrm{~A}$. This inductance drop is reasonable and will not impede on the characteristics in a converter. One could not conclude on a difference between the laminated shield and the plain shield. The slightly higher drop in inductance at $1 \mathrm{~A}$ for the inductor with laminated shield could be attributed to thickness variation in the process as electroplating can be sensitive to geometries.

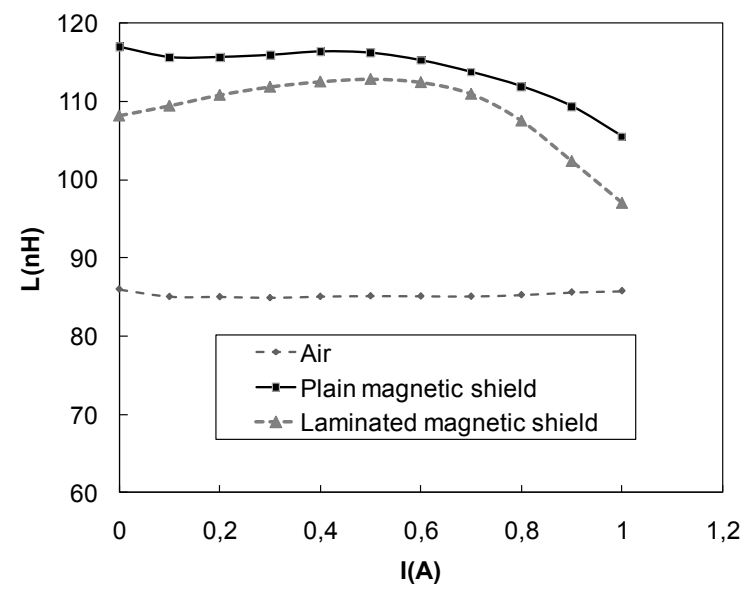

Figure 8. Equivalent series inductance (L) versus DC current measured with impedance analyzer at $1 \mathrm{MHz}$. 
We thus showed that a magnetic layer allows the shielding of eddy currents in the substrate. Moreover, the magnetic shield must be laminated in order to prevent eddy currents from developing in the magnetic layer itself. This solution is efficient and allows reaching high frequencies (up to $110 \mathrm{MHz}$, self-resonance frequency occurs at $400 \mathrm{MHz}$ ) with minimum losses.

\section{B. Integrated LC Filter}

Small-signal frequency responses obtained in parts A and B demonstrate that the presented integrated LC filter involves a spiral inductor and a 3D capacitor with high specific values $(110 \mathrm{nH}$ and $560 \mathrm{nF}$ for a total surface of $9 \mathrm{~mm}^{2}$ ), and a maximum working frequency beyond $110 \mathrm{MHz}$ in sinusoidal mode.

This new component thus achieves a good trade-off between obtainable electrical features and total footprint. This first prototype was mounted and wirebonded onto a PCB support and characterized in a test circuit represented in fig. 9 which comprises a switching cell based on the association of discrete components: a low $\mathrm{R}_{\mathrm{ON}}$ MOSFETs (IRLR3105), a Schottky diode (1N5819). The MOSFET's gate is controlled by a variable frequency generator followed by a low output impedance driver providing high current peaks. A snubber was added in parallel with the MOSFET to limit the oscillation on $V_{D S}$ due to a parasitic inductance in the switching cell loop. This circuit will allow evaluating the component under real conditions (large signals, non sinusoidal mode).

The circuit operating conditions were chosen to fit as follows: a switching frequency of $5 \mathrm{MHz}$; a duty cycle of 0.5 ; an input voltage of $3 \mathrm{~V}$ and a load resistance of $2.2 \Omega$.

Figure 10 shows measured waveforms: the inductor current $\mathrm{I}_{\mathrm{L}}$, the MOS transistor voltage $\mathrm{V}_{\mathrm{DS}}$ and the output voltage $\mathrm{V}_{\text {OUT }}$. The measured average output voltage is $\mathrm{V}_{\text {OUT }}=0.94 \mathrm{~V}$ with a voltage ripple $\Delta \mathrm{V}_{\text {OUT }}=460 \mathrm{mV}$. The current waveform in the inductor $\mathrm{I}_{\mathrm{L}}$ shows an average value of about $\mathrm{I}_{\mathrm{OUT}}=445 \mathrm{~mA}$ and a ripple $\Delta \mathrm{I}_{\mathrm{L}}=958 \mathrm{~mA}$. One can observe nonlinear tendencies for the current during increasing and decreasing time, both due to the inductor ESR and to the fact that the assumption $\Delta V_{\text {out }} \ll V_{\text {out }}$ is not satisfied.

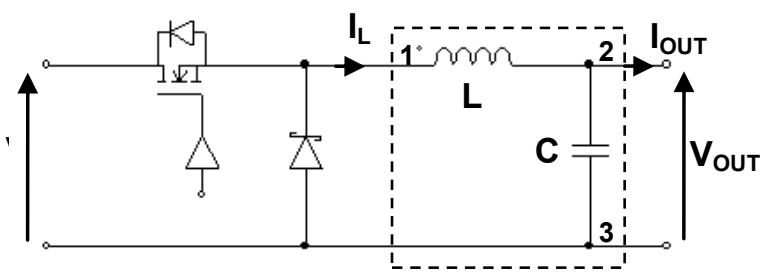

Fig. 9. Test circuit for integrated LC filter characterization. $(1),(2)$ and (3) correspond to the points referenced in Fig. 1a)

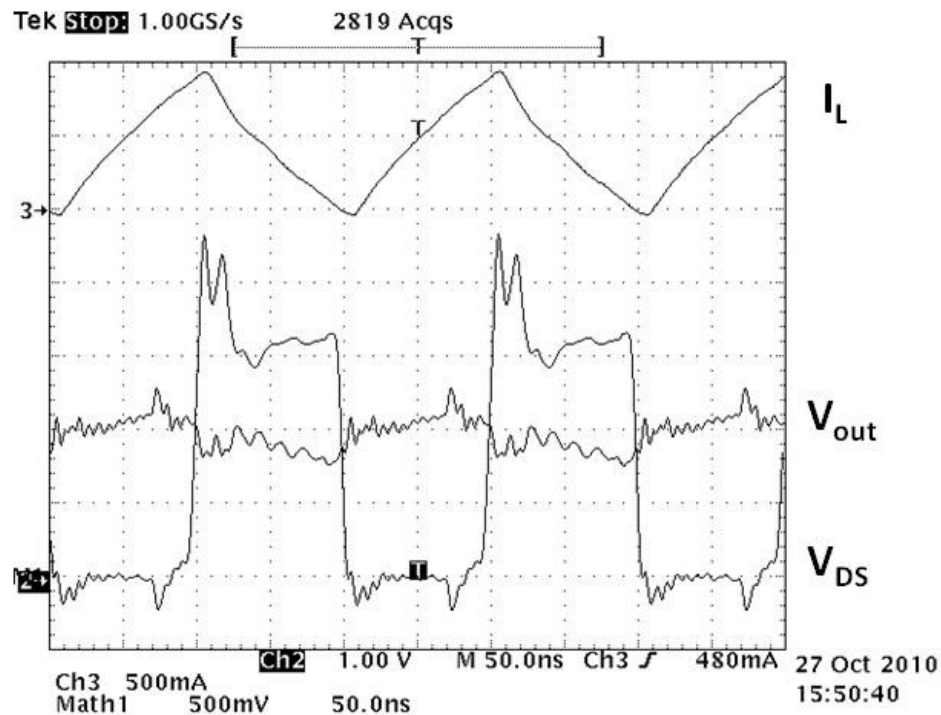

Fig. 10. Inductor current $\mathrm{I}_{\mathrm{L}}, \mathrm{V}_{\mathrm{DS}}$ and output voltage $\mathrm{V}_{\text {OUT }}$ at 5 $\mathrm{MHz}$.

TABLE 1. ELECTRICAL PERFORMANCE OF INTEGRATED FILTER IN THE TEST CIRCUIT AT 5MHZ.

\begin{tabular}{llll}
\hline \hline Symbol & & Calculated & Measured \\
\hline Pind & Inductor losses & $237 \mathrm{~mW}$ & $264 \mathrm{~mW}$ \\
Pcapa & Capacitor losses & $23 \mathrm{~mW}$ & -- \\
Pfilter & Total filter losses & $260 \mathrm{~mW}$ & \\
\hline Pcir & $\begin{array}{l}\text { Circuit (other than } \\
\text { passives) losses* }\end{array}$ & $243 \mathrm{~mW}$ & -- \\
& & \\
\hline Pin & Input power & $891 \mathrm{~mW}$ & $900 \mathrm{~mW}$ \\
Pout & Output power & $388 \mathrm{~mW}$ & $398 \mathrm{~mW}$ \\
\hline$\eta$ & Circuit efficiency & $43.5 \%$ & $45.6 \%$ \\
\hline \hline
\end{tabular}

*Circuit losses take into account the losses in the active component (Diode + MOSFET), the snubber, the input capacitor and the connection wires. The driver consumption was not taken into account.

In order to evaluate the integrated filter performance in a typical power electronics application, circuit simulations (PSIM) were performed using simple components models to validate the measured waveforms. In particular, intrinsic values and disturbances of each component (passive and active) were taken into account as well as all disturbances coming from the connections (wires and bonds). These simulations also allowed calculation of losses that are not directly measurable in the circuit. Table 1 reports the measured and calculated losses corresponding to the different parts of the test circuit.

Circuit efficiency, although quite low (about 45\%), shows that despite the use of linear models, there is a good correlation between calculation and measurements. This efficiency is affected by the output filter losses (which represents $52 \%$ of total losses) and in particular the losses in the inductor. Despite the technological improvement of the presented solution (thick conductors), the equivalent series resistance of the inductor is still too high for the targeted application and in particular for such current values ( $\mathrm{I}_{\text {OUT }}=445 \mathrm{~mA}$ ). 
Solutions to tackle this problem are to increase further the conductor thickness and to use efficiently a magnetic core that would allow the total conductor length to be reduced (thanks to an inductance increase).

Concerning the capacitor, the estimated losses are lower than the inductor. However, the capacitor ESR has an impact on the voltage output ripple visible in Fig. 9. The measured value $\Delta \mathrm{V}_{\text {OUT }}=460 \mathrm{mV}$ is indeed higher than the expected theoretical one that should be $50 \mathrm{mV}$ without parasitic elements of the capacitor branch. The voltage output ripple is both due to ESR of the capacitor (approximately $70 \%$ of the total ripple) and the parasitic resistance and inductance of the bondings. Wirebondings were used in these measurements but this solution should not be adopted for on-chip DC-DC converters where flip-chip BGA packaging is preferred. And as mentioned in section III-A, there are technological solutions to decrease further the intrinsic value of the capacitor ESR.

\section{CONCLUSION}

A fully integrated LC output filter for DC-DC application was designed, processed, and characterized. The feasibility of superposing a 3D capacitor and a spiral-type inductor with thick conductors while keeping resistive losses to a minimum at high frequencies was demonstrated. Beyond the challenge of technological steps successions, precise impedance measurement in a wide range of frequencies ( $10 \mathrm{kHz}$ to $4 \mathrm{GHz})$ proved the double interest of realizing a thin magnetic material layer between the inductor and the capacitor: the inductor value is modestly increased and the magnetic layer provides an excellent shielding against magnetic coupling with the substrate/capacitor. The component was characterized with waveforms typically found in DC-DC converters and a loss analysis was conducted at $5 \mathrm{MHz}$. The filter presents absolute values of inductance $(110 \mathrm{nH})$ and capacitance $(560 \mathrm{nF})$ that are well suited for DC-DC converters with switching operation in the range of several MHz. Furthermore, for such values, by stacking the two components, this arrangement offers an advantage in terms of integration.

The equivalent series resistances of both the inductor and the capacitor should be reduced further for achieving high converter efficiency and low output voltage ripple. Various technological solutions were proposed to improve the performance of each passive components but an optimized solution must take into account the specifications of the application where the integrated filter has to be implemented. The choice of the switching frequency, driven by the efficiency target, is then the principal parameter to design the output filter. The passive components optimization should be closely linked to a proper active components design in order to enable on chip DC-DC converter realization with high performance.

\section{ACKNOWLEDGMENT}

Technological developments were conducted in the microfabrication facilities at LAAS-CNRS.

\section{REFERENCES}

[1] Commercial switch-mode DC-DC converters datasheets (discrete: ADP2121, FAN5361, TS62601 and co-packaged IC/L: EP5368Q1, MIC3385)

[2] S. Abedinpour, B. Bakkaloglu and S. Kiaei, "A $65 \mathrm{MHz}$ switching rate, two-stage interleaved synchronous buck converter with fully integrated output filter," Proc. IEEE International Symposium on Circuits and Systems (ISCAS), p. 5315, 21-24 May 2006.

[3] H.J. Bergveld, R. Karadi and K. Nowak, "An inductive down converter system-in-package for integrated power management in battery-powered applications," Proc. IEEE Power Electronics Specialists Conference (PESC), pp. 3335-3341, 2008.

[4] M.H. Lim, J.D. van Wyk, F.C. Lee, K.D.T. Ngo, "A Class of Ceramic-Based Chip Inductors for Hybrid Integration in Power Supplies", IEEE Trans. Power Electron., vol. 23, pp. 1556 1564, May 2008.

[5] E Rodriguez, A Estrov, "Switching electrical power supply utilizing miniature inductors integrally in a PCB," US Patent 4,622,627, pp. 622-627, Nov. 11th 1986.

[6] S. K. Bhattacharya, R. R. Tummala, "New generation integral passives: materials, processes, and integration of resistors and capacitors on PWB substrates," J. of Materials Science: Materials in Electronics, vol. 11, pp. 253-268, 2000.

[7] A. Liang, J.F. van Wyk, F. C. Lee, "A Chip-level process for power switching module integration and packaging," Proc. 39th IEEE Industry Applications Conference IAS, p. 1932, 2004.

[8] W. Waffenschmidt, J. A. Ferreira, "Embedded passives integrated circuits for power converters," Proc. IEEE Power Electronics Specialists Conference (PESC), pp. 12-17, 2002.

[9] C.R. Sullivan, S; R. Sanders, "Design of microfabricated transformers and inductors for high-frequency power conversion," IEEE Trans. Power Electron., vol. 11, no. 2, pp. 228-238, March 1996.

[10] C.H. Ahn, M. G. Allen, "Micromachined planar inductors on silicon wafers for MEMS applications," IEEE Trans. Ind. Electron., vol. 45 (6), pp. 866-877, Dec. 1998.

[11] J.M. Boggetto, Y. Lembeye, J.P. Ferrieux, Y. Avenas, "Micro fabricated power inductors on silicon," Proc. IEEE 33rd Annual Power Electronics Specialists Conference (PESC), 2002.

[12] N. Wang, T. O’Donnell, R. Meere, F. M. F. Rhen, S. Roy, and S.C. O'Mathuna, "Thin-film-integrated power inductor on Si and its performance in an $8-\mathrm{MHz}$ buck converter," IEEE Trans. Magn., vol. 44, no. 11, pp. 4096-4099, 2008.

[13] Y. Sun, C. R. Sullivan, W. Li, D. Kopp, F. Johnson, S. T. Taylor, "Soft magnetic properties of obliquely deposited Co-Zr-O films," IEEE Trans. Magn., vol. 43, no. 12, pp. 4060-4064, 2007.

[14] C.R. Sullivan, "Integrating magnetic for on-chip power: challenges and opportunities", Proc. IEEE 2009 Custom Integrated Circuits Conference (CICC), San Jose, USA, pp. 291298, 13-16 Sept. 2009.

[15] F. Roozeboom, R.J.G. Elfrink, Th.G.S.M. Rijks, J.F.C.M. Verhoeven, A. Kemmeren and J.E.A.M. van den Meerakker, "High-density, low-loss MOS Capacitors for Integrated RF decoupling," International Symposium on Microelectronics, pp. 477-483, 2001.

[16] V. Lehmann, W. Hönlein, H. Reisinger, A. Spitzer, H. Wendt, J. Willer, "A novel capacitor technology based on porous silicon," Thin Solid Films Journal, vol. 276, pp. 138-142, 1996. 
[17] R. Ulrich and L. Schaper, "Materials options for dielectrics in integrated capacitors," International Symposium on Advanced Packaging Materials, pp. 38-43, 2000.

[18] M. Thomas, A. Farcy, N. Gaillard, C. Perrot, M. Gros-Jean, I. Matko et al., "Integration of a high density $\mathrm{Ta}_{2} \mathrm{O}_{5}$ MIM capacitor following 3D damascene architecture compatible with copper interconnects," Microelectronic Engineering Journal, vol. 83 (11-12), pp. $2163-2168,2006$

[19] H. Kim, P. C. McIntyre, "Atomic layer deposition of ultrathin metal-oxide films for nano-scale device applications," Journal of the Korean Physical Society, vol. 48 (1), pp. 5-17, January 2006.

[20] M. Brunet, E. Scheid, K. Galicka-Fau, M. Andrieux, C. Legros, I. Gallet et al., "Characterization of $\mathrm{ZrO}_{2}$ thin films deposited by MOCVD for high-density 3D capacitors," Journal of Microelectronics Engineering, vol. 86 (10), pp. 2034, 2009.

[21] E. Defaÿ et al., "Above IC integrated SrTiO3 high k MIM capacitors", Proc. of IEEE Solid-State Device Research Conference (ESSDERC), pp. 186-189, 2006.

[22] N. Menou, M. Popovici, S. Clima, K. Opsomer, W. Polspoel, B. Kaczer et al., "Composition influence on the physical and electrical properties of $\mathrm{Sr}_{\mathrm{x}} \mathrm{Ti}_{1-\mathrm{x}} \mathrm{O}_{\mathrm{y}}$-based metal-insulator-metal capacitors prepared by atomic layer deposition using TiN bottom electrodes," Journal of Applied Physics, vol. 106 (9), p. 094101, 2009.

[23] L. Huang, Z. Jia, I. Kymissis, S. O'Brien, "High-k capacitors and OFET gate dielectrics from self-assembled BaTiO3 and (Ba, $\mathrm{Sr}) \mathrm{TiO} 3$ nanocrystals in superparaelectric limit," Advanced Functional Materials, vol. 20, pp. 554-560, 2010.

[24] J. Sigman, G. L. Brennecka, P. G. Clem and B. A. Tuttle, "Fabrication of perovskite-based high-value integrated capacitors by chemical solution deposition," Journal of the American Ceramic Society., vol. 91 (6), pp. 1851-1857, 2008.

[25] R. Meere, T. O'Donnell, H.J. Bergveld, Ningning Wang, S.C. O'Mathuna, "Analysis of Microinductor Performance in a 20$100 \mathrm{MHz}$ DC/DC Converter," IEEE Trans. Power Electron., vol. 24, pp. $2212-2218$, Sept. 2009.

[35]
[26] M. Brunet, P. Dubreuil, E. Scheid, J-L. Sanchez, "Development of fabrication techniques for high-density integrated MIM capacitors in power conversion equipment," SPIE MOEMSMEMS Symposium Photonics West, Jan 2006.

[27] Ph. Artillan, "Design, modeling and realization of integrated inductive components for low power supplies and Microsystems," Ph.D. dissertation, Institut National des Sciences Appliquées, Toulouse, 133 p., 27 Novembre 2008.

[28] T. El Mastouli, J-P. Laur, J-L. Sanchez, M. Brunet, D. Bourrier, M. Dilhan, "Micro-inductors integrated on silicon for DC-DC converters," Proc. SPIE, MEMS and MOEMS, vol. 6882, 2008.

[29] F. Capy, J-P. Laur, M. Breil, F. Richardeau, M. Brunet, C. Caramel, P. Autin, J-L. Sanchez, "New self-controlled and selfprotected IGBT based integrated switch," Proc. IEEE International Symposium on Power Semiconductor Devices and IC's, Barcelona, June 2009

[30] F. Laermert and P. Schilp, "Method of anisotropically etching silicon", US Patent 5,501,893, March 1996.

[31] M. Brunet, P. Dubreuil, H. Mahfoz-Kotb, A. Gouantes, A-M. Dorthe, "Factorial experimental design applied to DRIE for optimised process in power electronics applications requiring high-aspect ratio trenches," Microsystems Technology, vol. 15, p. 1449,2009

[32] M. Brunet, M. Dilhan, D. Bourrier, H. Mahfoz Kotb, A. Benazzi, P. Dubreuil, E. Scheid, "Profile Enhancement of High Aspect Ratio Silicon Pores Made by DRIE with TMAH + IPA Bath," Proc. MicroMechanics Europe workshop (MME), Guimares, Portugal, 2007.

[33] G. M. Grivna, I.S.,Wan, S.C. Shastri, "Semiconductor device with high frequency parallel plate trench capacitor structure," United States Patent 6,984,860, 2006

[34] J.H. Klootwijk, K.B. Jinesh, W. Dekkers, J.F. Verhoeven, F.C. van den Heuvel, H.-D. Kim et al., "Ultrahigh capacitance density for multiple ALD-grown MIM capacitor stacks in 3-D silicon," IEEE Electron Device Lett., vol. 29 (7), pp. 740-742, 2008. 